\title{
Echocardiographic findings in prolapsed aortic cusp with vegetation
}

\author{
M. F. SHIU, D. J. COLTART, AND M. V. BRAIMBRIDGE \\ From the Departments of Cardiology and Cardiothoracic Surgery, St. Thomas' Hospital, London
}

SUMMARY A patient with severe aortic regurgitation showed abnormal echoes in the left ventricular? outflow tract compatible with aortic vegetation or flail aortic cusp. At operation, a pedunculated vege- $\frac{0}{2}$ tation on a prolapsed aortic cusp was found. The case illustrates some of the pitfalls in the echocardiographic distinction of the two conditions.

The distinction on echocardiographic findings between valvular vegetation and aortic valve cusp prolapse is not easy. We report here the echocardiographic features of a patient who had a vegetation on a prolapsed aortic valve cusp.

\section{Case report}

The patient, now aged 36, was a West Indian nurse with no history of rheumatic fever. Aortic regurgitation was first detected in 1965 but she was asymptomatic through three subsequent pregnancies. In 1973 she developed subacute bacterial endocarditis. Blood cultures grew Streptococcus viridans and she was successfully treated with a six-week course of intravenous penicillin. She made a full recovery but serial electrocardiograms and chest radiographs showed progressive cardiomegaly. Cardiac catheterisation in May 1975 confirmedo severe aortic regurgitation.

Aortic valve replacement was performed in $\stackrel{\mathbb{\perp}}{\circ}$ July 1975 . All three aortic valve cusps were slightly $\overrightarrow{0}$ thickened. The right coronary cusp had a $3 \mathrm{~mm}^{3}$ perforation in the centre. The left coronary cusp was prolapsed with a pedunculated mass of vegetation, $4 \mathrm{~mm}$ in diameter, attached to its free edge (Fig. 1). The valve was excised and replaced with a Starr Edwards prosthesis. Bacteriological cultureo of the valve tissue and vegetation was negative? She made an uneventful recovery and has sinceo returned to work.

ECHOCARDIOGRAPHIC FINDINGS

Echocardiograms were obtained the day before
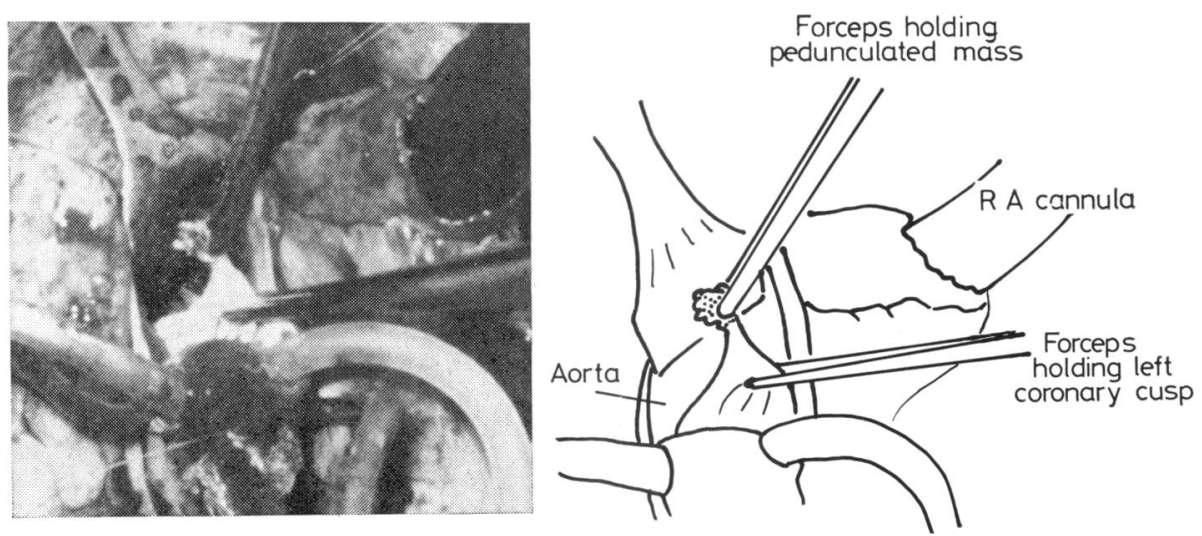

Fig. 1 Photograph of prolapsed aortic cusp and vegetation taken at the time of operation. 

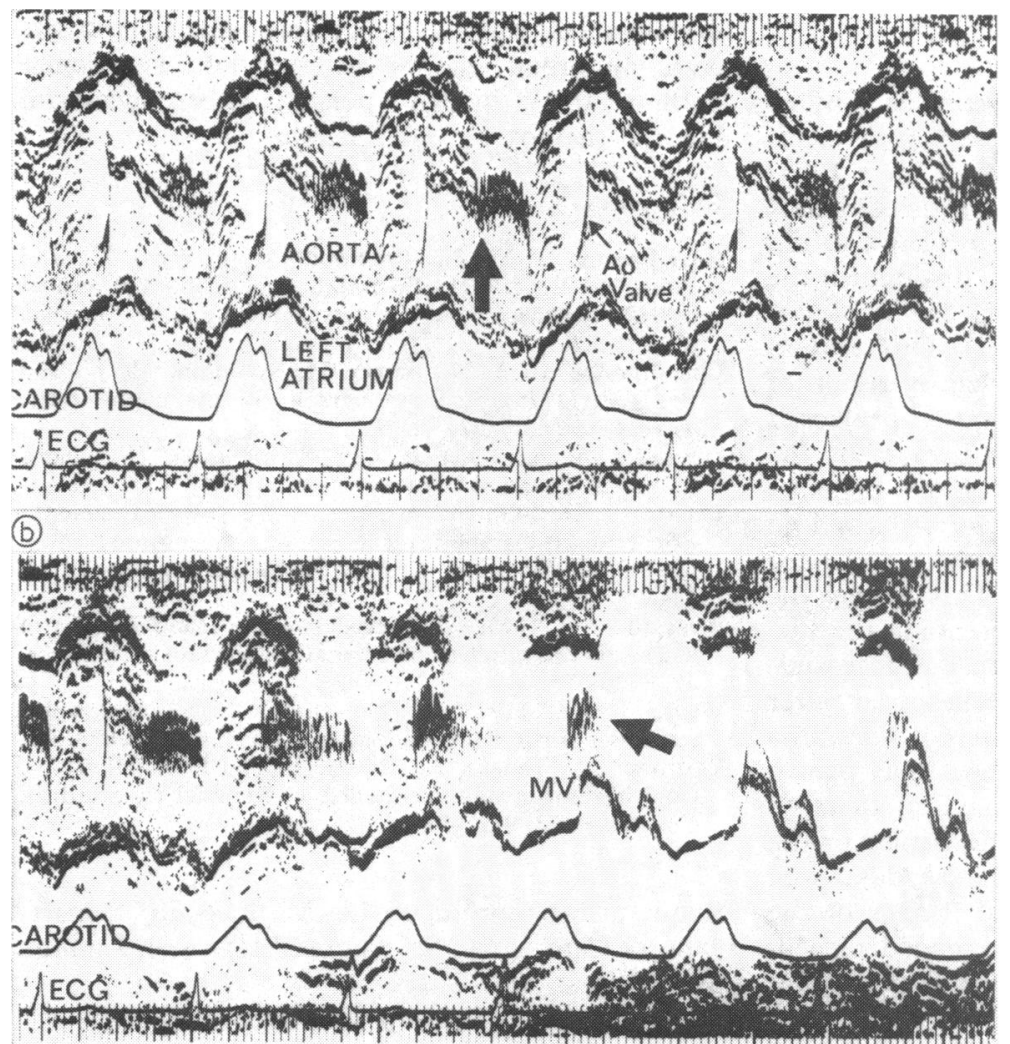

(c)

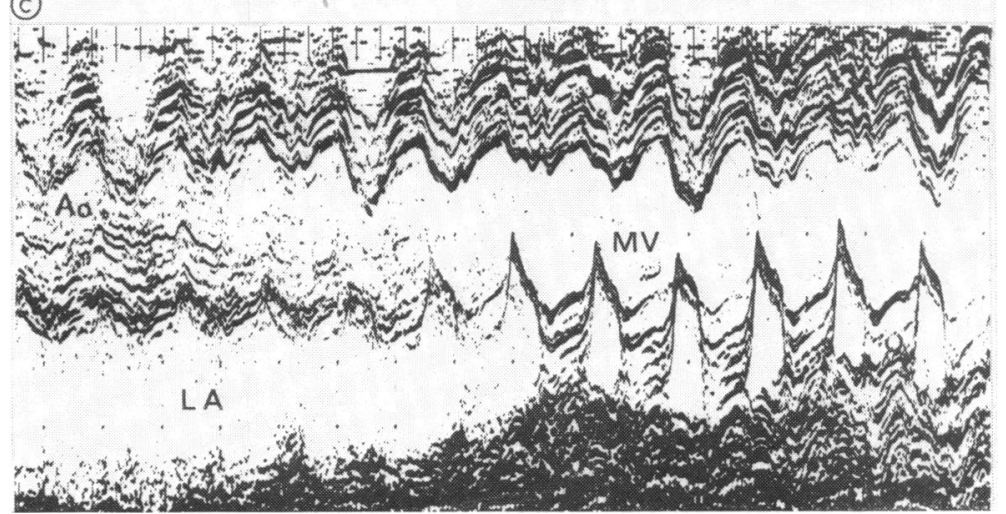

Fig. 2 Abnormal echoes (arrows) present at level of aortic valve (a) and in left venticular outflow tract (b) with no discontinuity between the two areas. (c) Postoperative echocardiogram showing no abnormal echoes in the left ventricular outflow tract. and two weeks after heart surgery. A Smith-Kline Ekoline 20A ultrasonoscope with a $2.25 \mathrm{MHz} 10 \mathrm{~cm}$ focused transducer was used. Records were made on a Cambridge photographic strip chart recorder. With the patient in the semi-recumbent position, several sweep recordings were made from the aortic valve to the apex in the long axis of the left ventricle.

Preoperative recordings (Fig. 2a and b) showed the normal box shaped configuration of the aortic valve echo with additional parallel echoes inside the box in systole. In diastole, an abnormal band of echoes showing high frequency oscillations was present both at the level of the valve (Fig. 2a) and in the left ventricular outflow tract in front of the anterior mitral leaflet (Fig. 2b). No discontinuity of the abnormal echoes was present as the transducer was swept between the two positions.

Postoperative examination showed no abnormal echoes in the left ventricular outflow tract (Fig. 2c). 


\section{Discussion}

Abnormal echoes in the left ventricular outflow tract have been described in prolapsed aortic cusps (Lee et al., 1974; Chandraratna et al., 1975; Wray, 1975a) and bacterial endocarditis (Gramiak and Waag, 1975; Wray, 1975b; Yoshikawa et al., 1976). A recent report attempted to distinguish the echocardiographic features between the two conditions (Chandraratna et al., 1977). Our patient had both conditions, presumably as a result of bacterial endocarditis on a previously prolapsed cusp. Two important points are illustrated by the present case. Firstly, comparison of our patient's echocardiograms with published reports showed no distinguishing features from either prolapsed aortic cusp or valve vegetation. This shows the inability of this technique to differentiate the two conditions. Secondly, while abnormal echoes suggestive of valve vegetation may disappear after successful treatment of the infection (Chandraratna et al., 1977), residual abnormal echoes may persist and thus can form no guide to medical therapy.

Operation was recommended in this patient on the grounds of progressive left ventricular dilatation. In retrospect there was also a real danger of the tenuously attached vegetation becoming detached, with forseeable consequences. This may be a point in favour of early valve replacement in patients with abnormal echoes in the left ventricular outflow tract, which persist after successful medical therapy for endocarditis.

\section{References}

Chandraratna, P. A. N., Robinson, M. J., Byrd, C., and Pitha, J. V. (1977). Significance of abnormal echoes in left ventricular outflow tract. British Heart fournal, 39, 381-389.

Chandraratna, P. A. N., Samet, P., Robinson, M. J., and Byrd, C. (1975). Echocardiography of the floppy aortic valve. Circulation, 52, 959-962.

Gramiak, R., and Waag, R. C. (1975). Cardiac Ultrasound. C. V. Mosby, Saint Louis.

Lee, C. G., Das, G., and Weissler, A. M. (1974). Characteristic echocardiographic manifestations in ruptured aortic valve leaflet (abstract). Circulation, 49 and 50, Suppl. III, 144.

Wray, T. M. (1975a). Echocardiographic manifestations of flail aortic valve leaflets in bacterial endocarditıs. Circulation, 51, 832-835.

Wray, T. M. (1975b). The variable echocardiographic features in aortic valve endocarditis. Circulation, 52, 658-663.

Yoshikawa, J., Tanaka, K., Owaki, T., and Kato, H. (1976). Cork-like aortic valve vegetation in bacterial endocarditis. Circulation, 53, 911-914.

Requests for reprints to Dr M. F. Shiu, Department of Cardiology, St. Thomas' Hospital, London SE1 7EH. 